\title{
Increased circulating follicular helper T cells with decreased programmed death-1 in chronic renal allograft rejection
}

\author{
Jian Shi ${ }^{1}$, Fengbao Luo ${ }^{1}$, Qianqian Shi ${ }^{1}$, Xianlin Xu ${ }^{1}$, Xiaozhou He ${ }^{1 *}$ and Ying Xia ${ }^{2^{*}}$
}

\begin{abstract}
Background: Chronic antibody-mediated rejection is a major issue that affects long-term renal allograft survival. Since follicular helper T (Tfh) cells promote the development of antigen-specific B cells in alloimmune responses, we investigated the potential roles of Tfh cells, B cells and their alloimmune-regulating molecules in the pathogenesis of chronic renal allograft rejection in this study.

Methods: The frequency of Tfh, B cells and the levels of their alloimmune-regulating molecules including chemokine receptor type 5 (CXCR5), inducible T cell co-stimulator (ICOS), programmed death-1 (PD-1), ICOSL, PDL-1 and interleukin-21 (IL-21), of peripheral blood were comparatively measured in 42 primary renal allograft recipients within 1-3 years after transplantation. Among them, 24 patients had definite chronic rejection, while other 18 patients had normal renal function.

Results: Tfh-cell ratio was significantly increased with PD-1 down-regulation in the patients with chronic renal allograft rejection, while B cells and the alloimmune-regulating molecules studied did not show any appreciable change in parallel.

Conclusions: The patients with chronic renal allograft rejection have a characteristic increase in circulating Tfh cells with a decrease in PD-1 expression. These pathological changes may be a therapeutic target for the treatment of chronic renal allograft rejection and can be useful as a clinical index for monitoring conditions of renal transplant.
\end{abstract}

Keywords: Chronic renal allograft rejection, Tfh cells, PD-1

\section{Background}

Renal transplantation remains an effective treatment for end-stage renal dysfunction [1], facilitating a return to normal health and prolonging life. However, antibodymediated rejection is a major issue that affects long-term renal allograft survival. Despite the rapid development of new immunosuppressive drugs for attenuating acute rejection, improving the long-term survival of grafts is still a challenge mainly because of chronic allograft rejection. The features of chronic renal allograft rejection are hypertension, proteinuria, progressive deterioration of graft function, peritubular capillary C4d deposition, presence of donor-specific antibodies (DSA) and morphological changes with transplant vasculopathy, glomerulopathy,

\footnotetext{
*Correspondence: czyyhxz@sina.cn; Ying.Xia@uth.tmc.edu

${ }^{1}$ Third Clinical College of Soochow University, Changzhou, Jiangsu, China

${ }^{2}$ The University of Texas Medical School at Houston, Houston, TX, USA
}

fibrosis and lymphocyte infiltration. However, the causes leading to chronic rejection are complex and not well understood yet [2].

Allograft rejection is characterized by an increase in activated CD4+ T-lymphocytes, especially regulatory and cytotoxic T cells, leading to an imbalance of immune responses in the transplant recipients [3, 4]. Functionally, $\mathrm{CD} 4+\mathrm{T}$ helper cells that interact with antigen-specific $\mathrm{B}$ cells are required for the production of alloantibodies [5]. Among them, Tfh cells, a recently defined subset of $\mathrm{CD} 4+\mathrm{T}$ cells, play a particular role in mediating B celldriven allogeneic responses. Tfh cells can migrate into germinal centers and promote B-cell activation and differentiation into immunoglobulin-producing plasmablasts or plasma cells [5]. They can express PD-1, CXCR5, ICOS, IL-21 and the transcription factor B-cell 
lymphoma 6 (Bcl-6) [6, 7], thereby displaying their regulatory functions.

Circulating Tfh cells, peripheral counterparts of conventional Tfh cells, express PD-1, CXCR5, ICOS and IL-21, but not Bcl-6 [5-7]. They play an important role in human humoral immunity through these functional molecules. Their abnormal activities are critically involved in the onset of several human diseases such as autoimmune disorders, cancer and infective diseases [7-10]. Therefore, an alteration in circulating Tfh cells may be correlated with disease conditions and might be used as a biomarker of certain diseases [11-13]. Moreover, recent clinical studies have shown that peripheral Tfh cells in the kidney transplant recipients with acute rejection can regulate B-cell alloreactivity and the number of these Tfh cells alters the immunization status and DSA levels [14]. However, their function and relevance to chronic renal allograft rejection are not known yet.

This study was conducted to explore the potential association between circulating Tfh cells and chronic rejection in kidney transplant recipients. The outcome results may provide a useful hint for clinical prediction of renal status after transplantation and for a potential new therapy for chronic allograft rejection.

\section{Methods}

This study was approved by the Institutional Ethics Committee of Third Affiliated Hospital of Soochow University, Jiangsu Province, China. Written-informed consent was obtained from all participants of the study.

\section{Subjects}

The patients with primary renal transplantation for 1-3 years were enrolled from October 2013 to December 2014. Totally 42 recipients were studied in this work, including 24 patients with chronic rejection (CR group) and 18 patients with normal renal function as the normal control (NC group). All of them received the treatment with cyclosporine A, methylprednisolone and mycophenolate mofetil or azathioprine after the renal transplantation. The diagnosis for chronic allograft rejection was confirmed by renal biopsy, biochemical measurements and immunological assays, including DSA as described in other studies [15-18]. In specific,the diagnostic criteria included 1) clinical evidence of slowly deteriorating graft function; 2) biopsy evidence and diffuse deposition of $\mathrm{C} 4 \mathrm{~d}$; and 3) the presence of circulating DSA at the time of biopsy. Their peripheral blood samples were collected in a standard way by the clinical laboratory of the hospital. All the subjects had no infective disease when sampling blood.

\section{Surface staining and flow cytometry analysis}

The whole blood was subjected to flow cytometry detection by a $\mathrm{BD}$ bioscience FACSCantoll cytometer with FACSDiva software for measuring the frequency of circulating Tfh cells and B cells as well as the expression of their surface markers. The following conjugated monoclonal antibodies were used to stain the cells: CD4-FITC, CXCR5-APC, ICOS-PE, PD-1-PE, CD19-PE-Cy5.5, ICOSL-PE and PDL-1-APC. The cells were incubated with the antibodies for $30 \mathrm{~min}$ at room temperature in the dark. Totally 50,000 lymphocytes were acquired in each sample. Data were analyzed using Flow Jo software 7.6.1.

\section{Enzyme-linked immunosorbent assay (ELISA)}

The levels of serum IL-21 were quantified by using the human IL-21 ELISA kit (eBioscience) according to the manufacturer's instructions. The concentration in each individual sample was calculated according to the standard curve.

\section{Statistical analyses}

All experimental data were analyzed by Graph Prism version 5.0. The results were expressed as mean \pm SD and subjected to $t$ test for statistical comparisons between the $\mathrm{NC}$ and $\mathrm{CR}$ groups. If a $p$-value was found to be less than 0.05 , the result would be considered statistically significant.

\section{Results}

\section{Demographics}

The general information of the renal transplant recipients was summarized in Table 1 . Gender and age were similar between $\mathrm{CR}$ and $\mathrm{NC}$ groups. The mean serum creatinine $(\mathrm{sCr})$ and blood urea nitrogen $(\mathrm{BUN})$ were almost three-fold higher in the CR patients than those of NC group $(p<0.001)$.

\section{Increased circulating Tfh cells in the CR patients}

To determine if chronic rejection was associated with an alteration in circulating Tfh cells in the renal transplantation recipients, we first evaluated the frequency of CD4 + CXCR5+ Tfh cells through flow cytometry. As shown in Fig. 1, the percentage of CD4+CXCR5+ Tfh cells among total CD4+ T cells was significantly increased in the $\mathrm{CR}$ group as compared to that of the $\mathrm{NC}$ group $(35.3 \pm 8.5 \%$ vs. $19.0 \pm 5.0, P<0.001)$.

Table 1 General information of the renal transplant patients

\begin{tabular}{lllcc}
\hline Group & $\begin{array}{l}\text { Gender } \\
\text { (male/female) }\end{array}$ & Age & $\begin{array}{l}\mathrm{SCr} \\
(\mu \mathrm{mol} / \mathrm{L})\end{array}$ & $\begin{array}{l}\mathrm{BUN} \\
(\mathrm{mmol} / \mathrm{L})\end{array}$ \\
\hline $\mathrm{NC}$ & $16 / 8$ & $42 \pm 7$ & $95.4 \pm 18.6$ & $5.3 \pm 1.6$ \\
$\mathrm{CR}$ & $12 / 6$ & $49 \pm 9$ & $277.0 \pm 124.3^{* * *}$ & $15.2 \pm 7.8^{* * *}$ \\
\hline
\end{tabular}

$N C$, normal control; $C R$, chronic rejection. $P<0.001^{* * *}$ vs. NC 

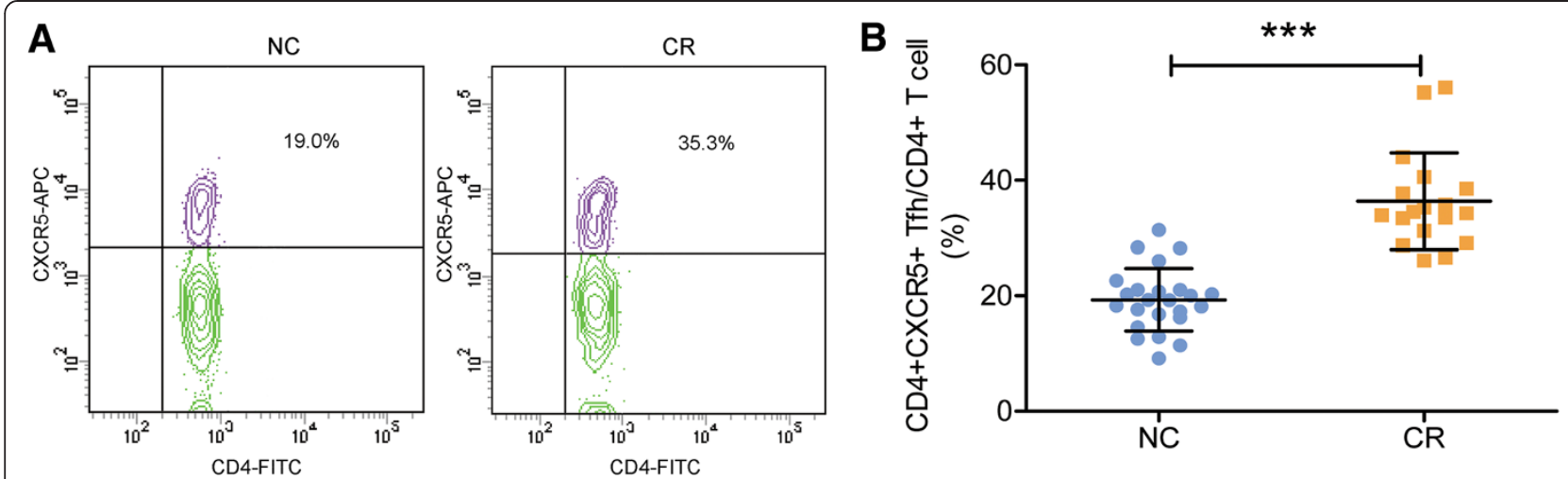

Fig. 1 Frequency of Tfh cells in the patients with renal allograft. $\mathbf{a}$, representative contour plots of the ratio of Tfh cells in the NC and CR groups, $\mathbf{b}$, mean values of the frequency of Tfh cells in the two groups. ${ }^{* *}, P<0.001$. Note a significant increase in Tfh cells in the CR group compared to that of the control group

Differential changes in PD-1, CXCR5, ICOS, and IL-21 of Tfh cells in the CR patients

We further detected the changes of PD-1, CXCR5 and ICOS in the high frequency of Tfh cells and found that PD-1 was significantly down-regulated in these Tfh cells (Fig. 2a). In sharp contrast, there were no significant changes in CXCR5 and ICOS in the CR group as compared to the $\mathrm{NC}$ group (Fig. $2 \mathrm{~b}$ and $\mathrm{c}$ ).

IL-21 is a biological hallmark of Tfh cells because this immune cytokine is produced by Tfh cells and is involved in mediating Tfh-B-cell interaction [6]. Therefore, we further measured the concentration of IL-21 in the serum of the CR patients (Fig. 3). Similarly as the changes in CXCR5 and ICOS, serum IL-21 did not show any significant change in the CR patients as compared to that of the control group $(406.9 \pm 123.9 \mathrm{pg} / \mathrm{ml}$ vs. $449.1 \pm 101.7 \mathrm{pg} / \mathrm{ml}, P>0.05)$.

\section{No changes in circulating B cells, PDL-1 and ICOSL in the CR patients}

Since B cells are key players in the graft rejection [19], we further determined the frequency of total B cells and compared their change with that of Tfh cells. The ratio of $\mathrm{B}$ lymphocytes was not significantly different between CR and NC groups (Fig. 4), unlike Tfh cells. Because PDL-1-expressing B cells interact with PD-1+ Tfh cells to regulate the maturation and survival of B cells [20], we next detected the expression of PDL-1 in B cells. Unlike the change in the PD-1 of Tfh cells, PDL-1 did not decrease in B cells at all in the CR group (Fig. 5a). Also, ICOSL had no significant change in the CR patients (Fig. 5b).

All these results suggest that the increase in circulating Tfh cells with PD-1 down-regulation is a specific and characteristic change in the CR patients.

\section{Discussion}

We have made a novel finding in this work, i.e., a major increase in circulating Tfh cells with a significant decrease in PD-1 in the patients with chronic renal allograft rejection. In sharp contrast, $\mathrm{B}$ cells and the alloimmune-regulating molecules such as CXCR5, ICOS, ICOSL, PDL-1 and IL-21 did not show any appreciable change in parallel.

Tfh cells display multiple features for their helper functions in secondary lymphoid organs or tissues with inflammation [21]. They migrate into B cell follicles of germinal centers [22] and thereby help B cells generate antibodies for humoral immunity [3, 6, 23]. In fact, Tfh cells, as an immune regulator, are critically involved in the pathological processes of many immune diseases [8]. In renal allograft rejection, the germinal center reactions are dependent on Tfh, while B cells are indispensable for the immune attack to the newly transplanted kidney [24].

Tfh cells express PD-1 [6], while B cells produce PDL-1, an endogenous ligand of PD-1 [19]. The PD-1/PDL-1 signaling has been shown to play an important role in regulating immune functions and affecting the activation of regulatory $\mathrm{T}$ cells, cytotoxic $\mathrm{T}$ cells and Dendritic cells [25]. Such signaling also influences the generation and differentiation of Tfh and B cells themselves [26]. Recent evidence suggests that blocking the PD-1 signaling induces an up-regulation of Tfh generation and differentiation, which may directly lead to autoimmune encephalomyelitis [27]. In contrast, stimulating this pathway can prolong the survival of the patients after cardiac allograft transplantation [28]. More recently, PD-1 ligands are found to protect the kidneys from ischemia reperfusion injury [29]. In fact, PDL-1, the endogenous ligand of PD-1, has been demonstrated as a required factor for peripheral transplantation tolerance and protection aganist chronic allograft rejection [30]. 


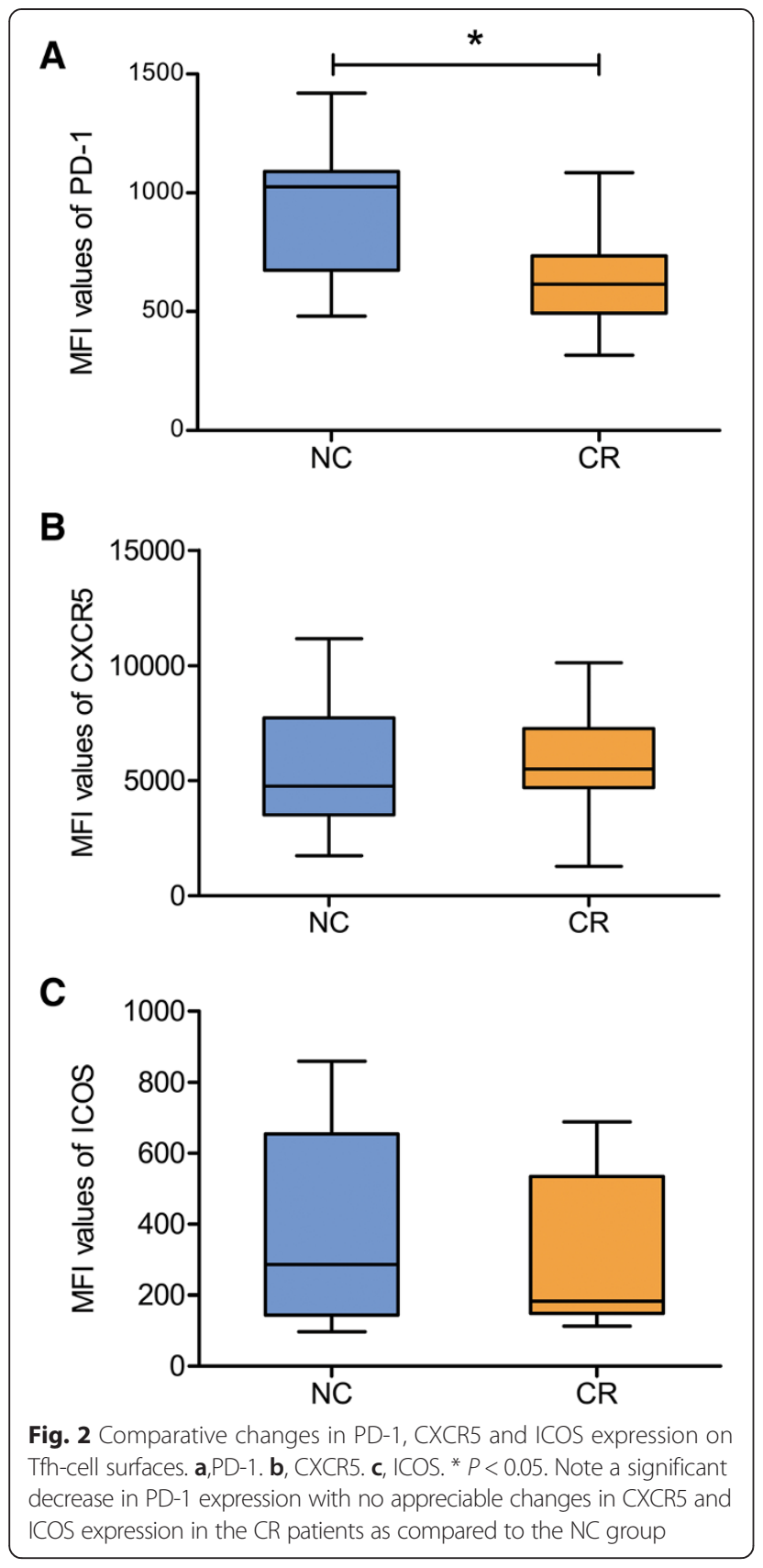

Taken together, PD-1 signaling is a key regulator for attenuating the Tfh cells and down-regulating the overreaction of humoral immunity against the transplanted kidneys. Therefore, the novel finding of the present study strongly suggests that the deficiency of PD-1 expression causes the increase in Tfh cells, thereby leading to an overreaction of humoral immunity against the allergenic organ, which may be a major reason for chronic allograft rejection.

Tfh and B cells also express many other immuneregulating molecules such as CXCR5, ICOS, ICOSL, and IL-21 $[6,19,26]$. All these molecules are actively

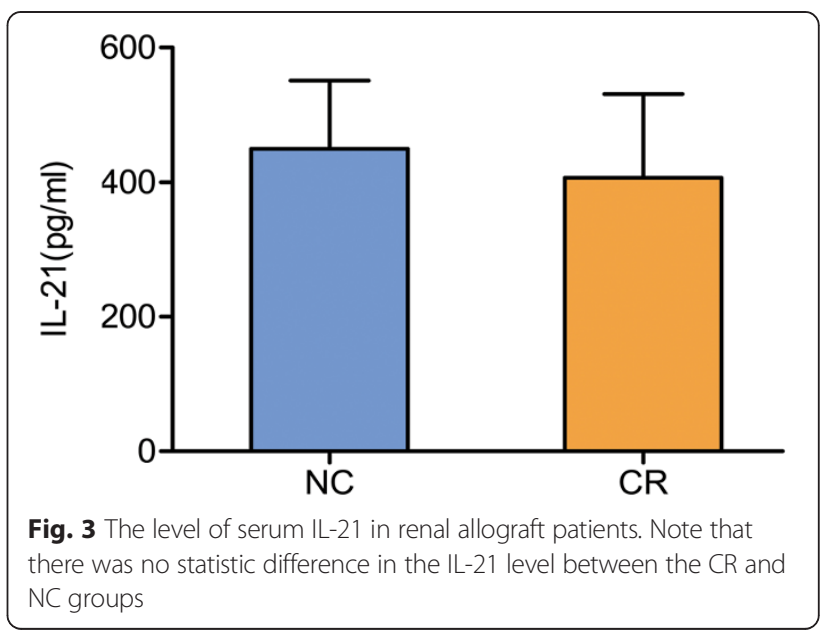

involved in the regulation of immune function [26]. For example, an increase in the expression of CXCR5 can enable Tfh cells to migrate into germinal centers [21]. On the other hand, ICOS, another surface receptor like PD-1, also mediate the generation, development and function of Tfh cells by activating ICOS/ICOSL signaling [31, 32]. Moreover, IL-21, a pro-inflammatory cytokine secreted by Tfh cells, has an important role in Tfh cell differentiation, B cell proliferation [33], and the expression of PD-1 [34] and CXCR5 [26]. However, all of these immune regulators did not shown any change in the patients with chronic allograft rejection. We are therefore confident that the deficient PD-1 expression with increased circulating Tfh cells is a specific and characteristic change in chronic allograft rejection.

In the lymph nodes, CD4+ CXCR5+ Tfh cells are more effective in helping $B$ cells than their peripheral counterparts [7]. Humoral response in the lymph nodes can be suppressed by anti-CD $40 \mathrm{mAb}$ via regulating Tfh cells [23]. In the transplanted kidneys with acute rejection, infiltrated Tfh cells have been found to participate in the antibody-mediated rejection [14]. However, little

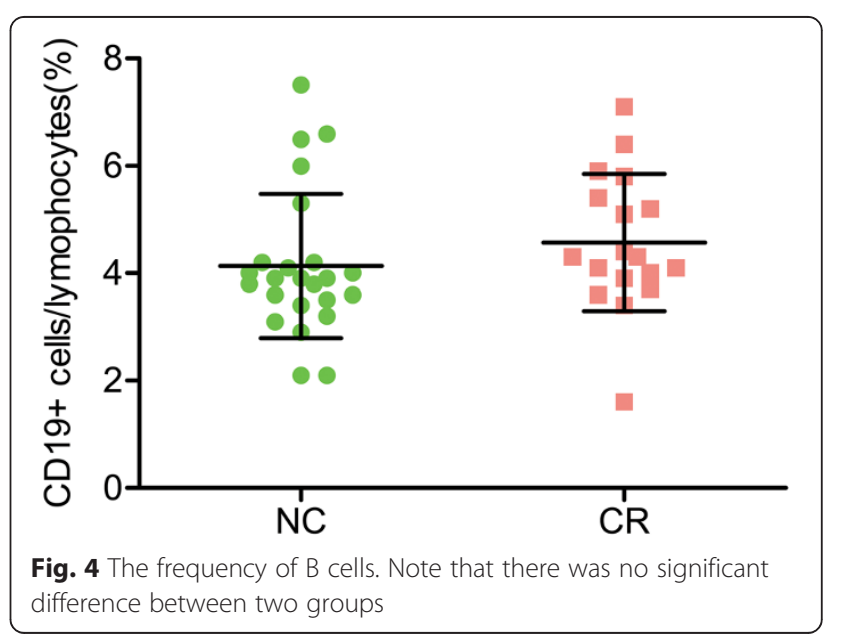




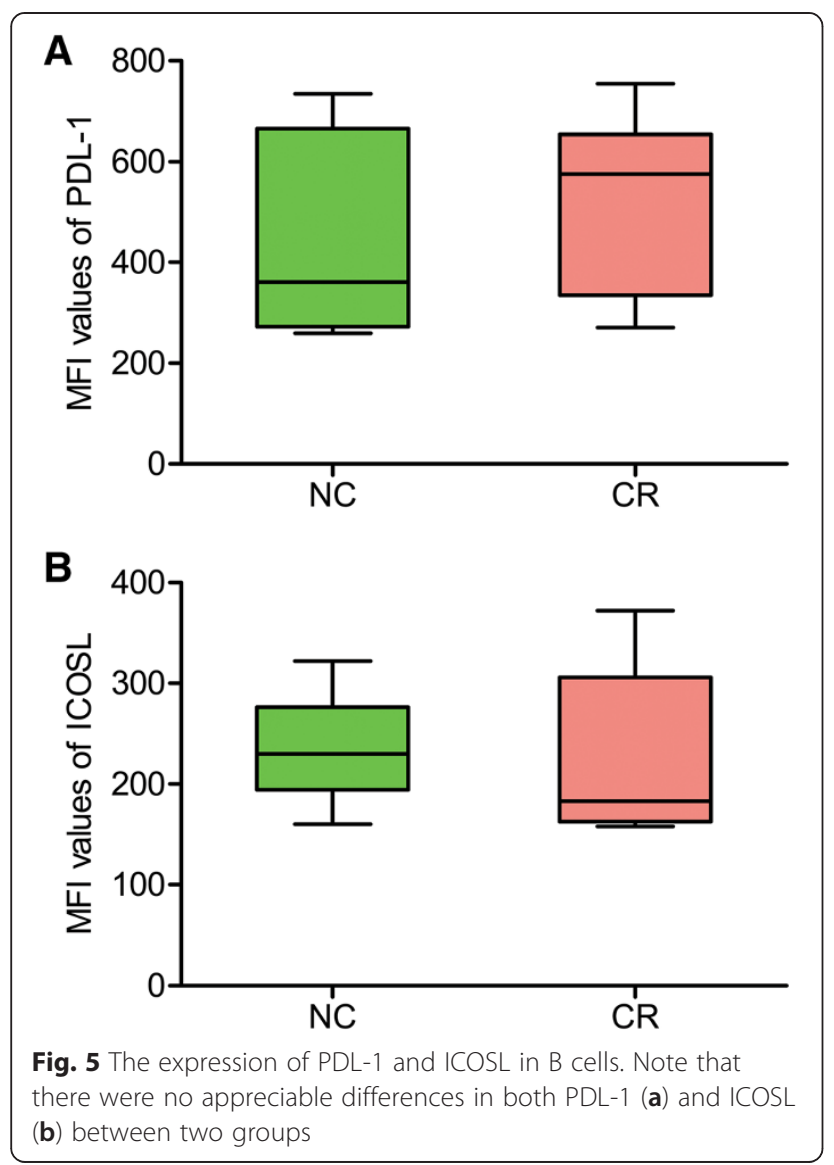

is known about the role of these special Tfh cells in the transplanted kidneys with chronic rejection. We speculate that the increase in circulating Tfh cells with a decrease in PD-1 expression might, at least partially, contributes to the genesis of the renal chronic rejection by migrating and infiltrating into germinal centers of renal allografts and lymphoid organs. We will further clarify this issue in our future work.

In addition, pre-existent DSA storing before renal transplantation and de-novo DSA developing after renal transplantation are associated with antibody-mediated rejection and allograft failure [35]. However, recent studies have shown that despite the numbers of circulating Tfh cells were higher in the patients with pre-existent DSA than those without pre-existent DSA, the levels of circulating Tfh cells were not different among the patients with or without de-novo DSA $[35,36]$. Therefore, the relationship between the frequency of circulating Tfh cells and the level of DSA in renal allograft rejection is not clear yet and needs more investigations.

\section{Conclusions}

Our first data show that decreased PD-1 expression may contribute to the increase in circulating Tfh cells in the patients with chronic renal allograft rejection. This finding provides a potential hint for a new target for the treatment of chronic rejection. Moreover, a dynamic change in the expression of PD-1 and the number of circulating Tfh cells may be used as an index for monitoring chronic allograft rejection after kidney transplantation as.

\section{Abbreviations}

Th: Follicular helper T cells; CXCR5: Chemokine receptor type 5; ICOS: Inducible T cell co-stimulator; PD-1: Programmed death-1; ICOSL: Inducible T cell co-stimulator ligand; PDL-1: Programmed death-1 ligand; IL-21: Interleukin-21; BCl-6: Transcription factor B-cell lymphoma 6; CR: Chronic rejection; NC: Normal control; ELISA: Enzyme-linked immunosorbent assay; sCr: Serum creatinine; BUN: Blood urea nitrogen; DSA: Donor-specific antibodies.

\section{Competing interests}

The authors declare that they have no competing interests.

\section{Authors' contributions}

$J S, X X, X H$ and $Y X$ conceived and designed the experiments. JS, FL and QS performed the experiments. JS analyzed the data. XH provided research reagents. JS and YX wrote the paper. All authors read and approved the final manuscript.

\section{Acknowledgements}

This work was supported by the National Natural Science Foundation of China (Grant No.81273267) . YX was partially supported by NIH (AT-004422).

Received: 26 May 2015 Accepted: 19 October 2015

Published online: 03 November 2015

\section{References}

1. Nankivell BJ, Alexander SI. Rejection of the kidney allograft. N Engl J Med. 2010;363:1451-62.

2. Halloran PF. Call for revolution: a new approach to describing allograft deterioration. Am J Transplant. 2002:2:195-200

3. Giaretta F, Bussolino S, Beltramo S, Fop F, Rossetti M, Messina M, et al. Different regulatory and cytotoxic CD4+ T lymphocyte profiles in renal transplants with antibody-mediated chronic rejection or long-term good graft function. Transpl Immunol. 2013;28:48-56.

4. Nankivell BJ, Chapman JR. Chronic allograft nephropathy: current concepts and future directions. Transplantation. 2006;81:643-54.

5. Morita R, Schmitt N, Bentebibel SE, Ranganathan R, Bourdery L, Zurawski G, et al. Human blood CXCR5(+)CD4(+) T cells are counterparts of T follicular cells and contain specific subsets that differentially support antibody secretion. Immunity. 2011;34:108-21.

6. Crotty S. Follicular helper CD4 T cells (TFH). Annu Rev Immunol. 2011;29:621-63.

7. Tangye SG, Ma CS, Brink R, Deenick EK. The good, the bad and the ugly TFH cells in human health and disease. Nat Rev Immunol. 2013;13:412-26.

8. King C, Tangye SG, Mackay CR. T follicular helper (TFH) cells in normal and dysregulated immune responses. Annu Rev Immunol. 2008;26:741-66.

9. Shi W, Li X, Cha Z, Sun S, Wang L, Jiao S, et al. Dysregulation of circulating follicular helper T cells in nonsmall cell lung cancer. DNA Cell Biol. 2014;33:355-60.

10. Slight SR, Rangel-Moreno J, Gopal R, Lin Y, Fallert-Junecko BA, Mehra S, et al. CXCR5(+) Thelper cells mediate protective immunity against tuberculosis. J Clin Invest. 2013;123:712-26.

11. Bentebibel SE, Lopez S, Obermoser G, Schmitt N, Mueller C, Harrod C, et al. Induction of ICOS + CXCR3 + CXCR5+ TH cells correlates with antibody responses to influenza vaccination. Sci Transl Med. 2013;5:176ra132.

12. Locci M, Havenar-Daughton C, Landais E, Wu J, Kroenke MA, Arlehamn CL, et al. Human circulating PD-1 + CXCR3-CXCR5+ memory Tfh cells are highly functional and correlate with broadly neutralizing HIV antibody responses. Immunity. 2013;39:758-69.

13. Pallikkuth S, Parmigiani A, Silva SY, George VK, Fischl M, Pahwa R, et al. Impaired peripheral blood T-follicular helper cell function in HIV-infected nonresponders to the $2009 \mathrm{H1N1} / 09$ vaccine. Blood. 2012;120:985-93.

14. Carla CB, Gretchen NG, Karin B. T Follicular Helper Cells in Transplantation: The Target to Attenuate Antibody-Mediated Allogeneic Responses? Curr Transpl Rep. 2014;1:166-72. 
15. Rascio F, Pontrelli P, Accetturo M, Oranger A, Gigante M, Castellano G, et al. A type I interferon signature characterizes chronic antibody-mediated rejection in kidney transplantation. J Pathol. 2015;237(1):72-84.

16. Hong YA, Kin HG, Choi SR, Sun IO, Park HS, Chung BH, et al. Effectiveness of Rituximab and Intravenous Immunoglobulin Therapy in Renal Transplant Recipients with Chronic Active Antibody-Mediated Rejection. Transplant Proc. 2012;44:182-4.

17. Chow KM, Szeto CC, Lai FM, Luk CC, Kwan BC, Leung CB, et al. Functional and histological improvement after everolimus rescue of chronic allograft dysfunction in renal transplant recipients. Ther Clin Risk Manag. 2015;11:829-35.

18. Kim MG, Kim YJ, Kwon HY, Park HC, Koo TY, Jeong JC, et al. Outcomes of combination therapy for chronic antibody-mediated rejection in renal transplantation. Nephrology(Carlton). 2013;18:820-6.

19. Nouel A, Simon Q, Jamin C, Pers JO, Hillion S. Regulatory B cells: an exciting target for future therapeutics in transplantation. Front Immunol. 2014;5:11.

20. Good-Jacobson KL, Szumilas CG, Chen L, Sharpe AH, Tomayko MM, Shlomchik MJ. PD-1 regulates germinal center B cell survival and the formation and affinity of long-lived plasma cells. Nat Immunol. 2010;11:535-42.

21. Schmitt N, Bentebibel SE, Ueno H. Phenotype and functions of memory Tfh cells in human blood. Trends Immunol. 2014;35:436-42.

22. Schaerli P, Willimann K, Lang AB, Lipp M, Loetscher P, Moser B. CXC chemokine receptor 5 expression defines follicular homing $T$ cells with $B$ cell helper function. J Exp Med. 2000;192:1553-62.

23. McHeyzer-Williams LJ, Pelletier N, Mark L, Fazilleau N, McHeyzer-Williams MG. Follicular helper $T$ cells as cognate regulators of B cell immunity. Curr Opin Immunol. 2009;21:266-73.

24. Kim EJ, Kwun, Gibby AC, Hong JJ, Farris AB, Iwakoshi NN, et al. Costimulation blockade alters germinal center responses and prevents antibody-mediated rejection. Am J Transplant. 2014;14:59-69.

25. Tsang JY, Li D, Ho D, Peng J, Xu A, Lamb J, et al. Novel immunomodulatory effects of adiponectin on dendritic cell functions. Int Immunopharmacol. 2011;11:604-9.

26. Park HJ, Kim DH, Lim SH, Kim WJ, Youn J, Choi YS, et al. Insights into the role of follicular helper T cells in autoimmunity. Immune Netw. 2014;14:21-9.

27. Ansari MJ, Salama AD, Chitnis T, Smith RN, Yagita H, Akiba H, et al. The programmed death-1 (PD-1) pathway regulates autoimmune diabetes in nonobese diabetic (NOD) mice. J Exp Med. 2003;198:63-9.

28. Ozkaynak E, Wang L, Goodearl A, McDonald K, Qin S, O'Keefe T, et al. Programmed death-1 targeting can promote allograft survival. J Immunol. 2002;169:6546-53.

29. Jaworska K, Ratajczak J, Huang L, Whalen K, Yang M, Stevens BK, et al. Both PD-1 Ligands Protect the Kidney from Ischemia Reperfusion Injury. J Immunol. 2015;194(1):325-33.

30. Tanaka K, Albin MJ, Yuan X, Yamaura K, Habicht A, Murayama T, et al. PDL is required for peripheral transplantation tolerance and protection from chronic allograft rejection. J Immunol. 2007;179:5204-10.

31. Gigoux M, Shang J, Pak Y, Xu M, Choe J, Mak TW, et al. Inducible costimulator promotes helper T-cell differentiation through phosphoinositide 3-kinase. Proc Natl Acad Sci. 2009;106:20371-6.

32. Hams E, McCarron MJ, Amu S, Yagita H, Azuma M, Chen L, et al. Blockade of B7-H1 (programmed death ligand 1) enhances humoral immunity by positively regulating the generation of $\mathrm{T}$ follicular helper cells. J Immunol. 2011;186:5648-55.

33. Nurieva Rl, Chung Y, Hwang D, Yang XO, Kang HS, Ma L, et al. Generation of $T$ follicular helper cells is mediated by interleukin-21 but independent of Thelper 1, 2, or 17 cell lineages. Immunity. 2008;29:138-49.

34. Jacob J, Przylepa J, Miller C, Kelsoe G. In situ studies of the primary immune response to (4-hydroxy-3-nitrophenyl)acetyl. III. The kinetics of $V$ region mutation and selection in germinal center B cells. J Exp Med. 1993;178:1293-307.

35. de Graav GN, Dieterich M, Hesselink DA, Boer K, Clahsen-van Groningen MC, Kraaijeveld $\mathrm{R}$, et al. Follicular $\mathrm{T}$ helper cells and humoral reactivity in kidney transplant patients. Clin Exp Immunol. 2015;180:329-40

36. Lee PC, Zhu L, Terasaki PI, Everly MJ. HLA-specific antibodies developed in the first year posttransplant are predictive of chronic rejection and renal graft loss. Transplantation. 2009;8:568-74.

\section{Submit your next manuscript to BioMed Central and take full advantage of:}

- Convenient online submission

- Thorough peer review

- No space constraints or color figure charges

- Immediate publication on acceptance

- Inclusion in PubMed, CAS, Scopus and Google Scholar

- Research which is freely available for redistribution

Submit your manuscript at www.biomedcentral.com/submit 